\title{
Will Poaching Exterminate Kenya's Rhinos?
}

\author{
Kes Hillman and Esmond Martin
}

\begin{abstract}
These extracts from a memorandum by two scientists resident in Kenya describe the desperate situation to which poaching has brought the black rhino in East Africa. Dr Hillman is Chairman of the IUCN/SSC African Rhino Group.
\end{abstract}

Poaching for the commercial use of their horns has reduced the populations of black rhinoceros Diceros bicornis in East Africa to between one-fifth and onetenth of what they were five years ago, while the northern white rhinoceros Ceratotherium simum cotton $i$ has for a number of years been reduced to a handful of relict populations in a fraction of their former ranges in Sudan, Uganda, Zaire and the Central African Republic. The southern white rhinoceros Ceratotherium simum simum was saved from extinction only by severe conservation strategies.

In 1969 the rhino population of Kenya may have been in the region of 15,000 to 20,000 (based on combining estimates for different areas). At the beginning of the century it must have been considerably higher on the basis of the numbers that were observed and killed by early hunters. By 1977 there were probably between 2000 and 4000 rhinos in the country (a figure based on local censuses and a census of all the rangelands of Kenya by the Kenya Rangeland Ecological Monitoring Unit). But in 1979, there are fewer than 1500 - a reduction of 90 per cent in 10 years.

Census results indicate possible losses of up to 95 per cent in Tsavo, 80 per cent in Amboseli, Kenya; 70 per cent in Ngorongoro, $70-80$ per cent in Ruaha, 80 per cent in Tarangire and 80-85 per cent in Manyara, Tanzania, over the last six years. Last year 25 were killed in Manyara alone, and probably fewer than 12 are left alive, of which perhaps 3 or 4 are reproductive females. More than 40 were killed in Meru National Park, Kenya, in the last year.

For a species that exists largely as solitary individuals at a naturally low density, the severe declines cause further problems by reducing the densities of rhinos to such an extent that the probabilities of reproduction may also be greatly reduced. In addition, they are easy animals to stalk, and those that are left are showing evidence of extreme disturbance in response to the harassment. The potential reproductive rate of the decimated populations may therefore also be lowered, and some populations face total extinction unless strong measures are taken.

\section{Prices For Horns}

Recent prices that we have been quoted for rhino horn range from the equivalent of $\$ 250$ to $\$ 750$ per $\mathrm{kg}$. Compare this with the minimum wage for a ranger in Tanzania, equivalent to $\$ 56$ per month. For this he may have to expose himself to considerable danger with inadequate weapons or back-up. Yet many of them are dedicated to the job. However, more funds and greater motivation are badly needed. Funds will also be needed for strong conservation strategies to save some threatened populations.

Examination of the East African statistics on the legal export of rhino horn from 1972 to 1976 shows that about four metric tonnes have been exported 
annually, 95 per cent of it from Kenya. Over this five-year period the main markets of East African rhino horn have been China, Hong Kong, and North Yemen. In 1976, the bulk went to North Yemen. *

\section{Urgent Action}

If the rhino horn exports were to continue at the same annual rate as the official East African records show for the two-year period 1975 and 1976, then within two years it would be possible to eliminate the remaining rhinos in Kenya. In practice, the law of diminishing returns makes total extinction unlikely, but it in no way reduces the serious urgency of the situation.

The problem is urgent. We applaud the recent statement that the Hong Kong Government has banned importation of rhino horn products. But the North Yemen and China imports still create an incentive to kill rhinos. Action-oriented research on the nature of the trade and on the status and conservation of the remaining rhino populations is essential. The IUCN/SSC African Rhino Group will act as a central clearing house and co-ordinating body for information and action on African rhinos.

In Kenya groups of individuals from Government Departments and nongovernmental organisations have been working together to develop the most effective conservation strategies for rhinos in the country, and similar approaches will be made in other African countries with important rhino populations.

They are attacking the problem at all levels, from support by Heads of State and international pressure on the trade, through control of illegal trading and poaching within the country, increasing public awareness for funds, public pressure and involvement of rural people in protecting the rhinos they live close to, by increasing their incentive to do so, down to the establishment of sanctuaries for rhinos, and movement of them from unviable areas. More of this is needed elsewhere.

Dr Kes Hillman, P O Box 60642, Nairobi, Kenya. Chairman, IUCN/SSC African Rhino Group. Dr Esmond Bradley Martin, P O Box 15510, Nairobi, Kenya.

* For details of the trade see the article on page 153.

\section{International Zoo Yearbook}

Volumes 18 and 19 of The International Zoo Yearbook feature penguins and reptiles respectively. Happily, most species of the former are secure in the wild - but many of the reptiles mentioned in Volume 19 are threatened or endangered, and the articles on their captive breeding have an importance exceeding that of the zoo exhibit. Volume 19 also contains reports on the studbooks for Edwards's pheasant, brown hyaena and rare leopards, and Volume 18 for snow leopard. Captive breeding articles include, in Volume 18, West African dwarf crocodile, white-tailed sea eagle, white-faced saki, woolly monkey, Prevost's squirrel, tayra, zorilla and golden cat, and, in 19, scarlet ibis, nene, orang-utan, maned wolf, spectacled bear, Chinese hog badger and binturong.

In both volumes the invaluable reference section includes a census of rare animals in captivity, designed to help zoos 'to draw up a coordinated international breeding policy for rare animals'. The importance of this can be seen in, for example, the Conservation Section of Volume 18, where a useful summary of one of the world's most endangered deer, the Manipur brow-antlered deer (down to 14 animals in 1975), gives encouraging news of inter-zoo cooperation by seven Indian zoos. By January 1977 the captive population was 49. (P.J.S. Olney, editor, Zoological Society of London. Volume 18, £14, $\$ 28$; Volume $19, £ 17, \$ 34$.) 